\title{
Implementasi Pembelajaran Tematik di Kelas 2 SD Negeri Demangan Yogyakarta
}

\author{
Mohammad Syaifuddin \\ Pascasarjana Universitas Islam Negeri Sunan Kalijaga Yogyakarta; \\ email: m.syaifuddin51kom@gmail.com
}

Diterima: 10 Oktober 2017. Disetujui: 12 November 2017. Dipublikasikan: Desember 2017

\begin{abstract}
This research aims to describe the planning, implementing, and assessing integrated thematic learning in SD Negeri Demangan Yogyakarta. The research is descriptive qualitative research. The subjects were the teacher, students of class $2 A$, and the headmaster. The data collection techniques which are used are observation, interviews, and documentation. The data were analyzed by using steps of data reduction, data display, and conclusion. Examination techniques of the validity of the data using triangulation techniques and sources. The results showed that an integrated thematic planning that teachers do already have the minimum criteria lesson planning. The implementation of integrated thematic learning has led to integrated thematic learning characteristics, including the integration of subjects using the Basic Competency $(K D)$ subjects; each Basic Competency has its own material. On the learning activity which is implemented by the teacher, the scientific approach was implemented by the teacher with modern supporting media such as the use of LCD projector, CCTV camera, and learning aids.
\end{abstract}

\begin{abstract}
Abstrak
Penelitian ini bertujuan untuk mendeskripsikan perencanaan, pelaksanaan, dan penilaian pembelajaran tematik terpadu di SD Negeri Demangan Yogyakarta. Penelitian ini merupakan penelitian deskriptif kualitatif. Subjek penelitian ini adalah guru kelas, siswa kelas 2A, dan kepala sekolah. Teknik pengumpulan data yang digunakan adalah observasi, wawancara, dan dokumentasi. Data dianalisis menggunakan langkah-langkah reduksi data, display data, dan penarikan kesimpulan. Teknik pemeriksaan keabsahan data dengan menggunakan triangulasi teknik dan sumber. Hasil penelitian menunjukkan bahwa perencanaan tematik terpadu yang dilakukan guru sudah memuat kriteria minimal perencanaan pembelajaran. Pelaksanaan pembelajaran tematik terpadu sudah memunculkan karakteristik pembelajaran tematik terpadu, diantaranya menggunakan pemaduan mata pelajaran Kompetensi Dasar (KD) mata pelajaran, setiap KD memiliki materi tersendiri. Pada kegiatan pembelajaran yang dilaksanakan guru, pendekatan saintifik sudah dilaksanakan dengan media pendukung yang sudah modern seperti penggunaan LCD proyector, Kamera CCTV dan alat peraga pembelajaran.
\end{abstract}

Kata Kunci: Implementasi, Pembelajaran Tematik

(C) 2017 URPI, FTK UIN Raden Intan Lampung

\section{PENDAHULUAN}

Dunia pendidikan semakin dituntut untuk lebih efektif dan menyenangkan. Meningkatnya kemajuan suatu bangsa, dapat dilakukan dengan upaya meningkatan mutu pendidikan (Irwandani \& Juariyah, 2016). Pendidikan merupakan hal terpenting dalam kehidupan setiap orang (Sari, Farida, \& Syazali, 2016), sehingga dalam pendidikan memerlukan dasar nilai-nilai ideal yang dapat menjadi sumber kebenaran dan kekuatan yang dapat mengantarkan pada apa yang dicitacitakan. Dasar tersebut juga harus menjadi standar nilai dalam mengevaluasi aktivitas pendidikan yang diselenggarakan 
(Humaniora, 2011). Pemilihan model pembelajaran sangat menentukan akan keberhasilan dan tingkat penguasaan siswa terhadap suatu pelajaran (Erlinda, 2017; Gumrowi, 2016). Proses belajar mengajar di kelas dapat mempengaruhi mutu pendidikan, Sehingga Guru dituntut dapat memilih model pembelajaran yang dapat memacu semangat setiap siswa untuk secara aktif ikut terlibat dalam pengalaman belajarnya (Irwandani \& Rofiah, 2015; Rusman, 2012; Yulianti \& Putra, 2012). Penggunaan model pembelajaran yang tidak sesuai dengan keadaan suatu sekolah akan berdampak pada keberhasilan siswa memahami konsep yang dipelajari (Juleha, Khuzaemah, \& Cahyani, 2014; Mulyadi, 2015; Wijayanti, Maharta, \& Suana, 2017).

Pencapaian keberhasilan belajar mengajar memerlukan dukungan dari guru, siswa dan sekolah (Komikesari, 2016). Guru dapat mengetahui kelemahan siswa serta dapat merancang pembelajaran yang sesuai dengan proses berpikir siswa (Yanti \& Syazali, 2016). Model pembelajaran tematik bukanlah hal yang asing bagi kalangan guru, khususnya guru sekolah dasar yang wajib menerapkan pembelajaran model tematik pada kelas rendah. Pembelajaran tematik merupakan model yang harus diterapkan sesuai yang ada dalam kurikulum yang ada saat ini, dijelaskan bahwa pembelajaran tematik harus digunakan dalam proses belajar mengajar di sekolah dasar, karena pembelajaran tematik bertujuan menyampaikan konsep pembelajaran secara utuh dan menyeluruh kepada siswa sehingga tujuan pendidikan nasional untuk membentuk pranata sosial yang kuat dan berwibawa akan terwujud (Kemendikbud., 2012).

Proses pembelajaran pada prinsipnya merupakan proses komunikasi. Masalahnya adalah bagaimana agar proses komunikasi itu berjalan dengan efektif, sehingga pesan yang ingin disampaikan dapat diterima siswa secara utuh (Saputro \& Soeharto, 2015), dari interaksi demikian anak memperoleh pengetahuan dan pengalaman. Ketika anak berinteraksi dengan lingkungannya ini ia belajar banyak hal, dari subjek matematik, ilmu pengetahuan alam ilmu pengetahuan sosial sampai humaniora. Karena ilmu-ilmu sebagaimana disebutkan di atas ada di masyarakat dan lingkungan sekitar anak, baik ilmu itu sebagai konsep yang diwacanakan oleh masyarakat maupun praktik dari penerapan ilmu-ilmu tersebut (Kadir \& Asrohah, 2015).

Pembelajaran dalam hal perencanaan materi pembelajaran tematik sebaiknya menggunakan materi yang bisa dipadukan. Selanjutnya pembelajaran Kurikulum 2013 di SD dilakukan dengan menggunakan pembelajaran tematik integratif. Maksudnya pembelajaran integratif, dimana kompetensi-kompetensi mata pelajaran yang dipadukan dan diikat dalam sebuah tema kemudian menjadi materi belajar bagi peserta didik di kelas (Prasetyo, 2017). Pembelajaran tematik terpadu dipilih pada proses pembelajaran tingkat sekolah dasar karena memiliki karakteristik menarik untuk pengembangan pembelajaran peserta didik (Mulyadin, 2016).

Pembelajaran tematik lebih menekankan pada keterlibatan siswa dalam proses belajar secara aktif dalam proses pembelajaran, sehingga siswa dapat memperoleh pengalaman langsung dan terlatih untuk dapat menemukan sendiri berbagai pengetahuan yang dipelajarinya. Melalui pengalaman langsung siswa akan memahami konsepkonsep yang mereka pelajari dan menghubungkannya dengan konsep lain yang telah dipahaminya. Pembelajaran tematik juga mempunyai kaitan dengan psikologi perkembangan karena isi materi didasarkan pada tahap perkembangan peserta didik selain itu psikologi belajar 
juga diperlukan karena mempunyai kontribusi (Antrock, 2011).

Studi mengenai implementasi pembelajaran tematik di sekolah dasar umum dilakukan untuk mengetahui sejauh mana sekolah melaksanakan pembelajaran tematik dimulai sejak diberlakukannya kurikulum 2013 terutama yang menjadi pusat penelitian adalah kelas rendah sebagai gerbang pemahaman tematik (Dwi parwati, 2016). Studi tentang implementasi sebelumnya berfokus pada dokumen pembelajaran tematik tidak menyeluruh ke semua aspek. Oleh sebab itu, maka penelitian ini memfokuskan pada pembelajaran tematik yang dilihat dari sudut pandang dokumen pembelajaran, pelaksanaan di lapangan dan faktor-faktor lain seperti kualitas guru yang baru direkrut untuk kelas 2 di SDN Demangan. Hasil wawancara awal dengan kepala sekolah menyebutkan bahwa pembelajaran tematik mengalami sedikit kesulitan untuk guru-guru lama yang berumur dan guru yang baru direkrut.

Untuk mengetahui lebih jauh mengenai implementasi pembelajaran tematik di kelas rendah, maka peneliti melakukan penelitian dengan menfokuskan pada: 1) aspek perencanaan; 2) aspek pelaksanaan; dan 3) aspek penilaian yang dilihat dari dokumen pembelajaran, pelaksanaan di lapangan dan komentar guru dan siswa.

\section{METODE PENELITIAN}

Penelitian ini termasuk pada penelitian deskriptif kualitatif jika digolongkan berdasarkan tujuannya. Penelitian ini dilaksanakan di SD Negeri Demangan, khususnya di kelas 2 dengan wali kelas Bapak Sudaryanto, S.Pd. Populasi dalam penelitian ini adalah seluruh kelas 2 SD Demangan yang berjumlah 59 dan diambil sampling di kelas A. Penelitian ini, peneliti menggunakan teknik pengumpulan data berupa observasi, wawancara, dan dokumentasi. Aktivitas analisis data yang dilakukan dalam penelitian ini, yaitu data reduction, data display, dan conclusion drawing/verification menggunakan uji kredibilitas yaitu, triangulasi (sumber dan teknik) dan member check.

\section{HASIL DAN PEMBAHASAN}

Dalam implementasi, perencanaan menjadi awal proses sebelum pelaksanaan dan penilaian. Tujuan pembelajaran dapat tercapai dengan efektif dan efisien jika direncanakan dengan baik. Perencanaan yang dibuat dituangkan ke dalam Rencana Pelaksanaan Pembelajaran (RPP). Setiap RPP mengacu dari silabus atau kurikulum yang berlaku, kemudian dikembangkan sesuai dengan kondisi di satuan pendidikan. RPP dikembangkan secara rinci dari suatu materi pokok atau tema tertentu yang mengacu pada silabus untuk mengarahkan kegiatan pembelajaran siswa dalam upaya mencapai Kompetensi Dasar (KD), Panduan Teknis Penyusunan RPP di sekolah (Kemdikbud, 2013). RPP disusun berdasarkan tema/subtema atau KD yang dilaksanakan dalam satu atau lebih pertemuan.

Berdasarkan hasil wawancara dengan guru kelas 2A (Sudaryanto), RPP dibuat guru secara mandiri, namun sebelumnya guru telah menerima pelatihan serta diskusi dalam Kelompok Kerja Guru (KKG) untuk penyusunan RPP yang baik. Hasil triangulasi wawancara dengan kepala sekolah juga menjelaskan RPP disusun oleh guru itu sendiri atau disusun secara mandiri.

Berdasarkan hasil penelitian, RPP yang digunakan guru sebagai pedoman dalam melaksanakan kegiatan pembelajaran di kelas sudah menggunakan tema. Dalam penetapan tema, guru menggunakan tema-tema yang dekat dengan kehidupan siswa. Temuan ini mendukung pendapat Trianto bahwa penetapan tema dimulai dari lingkungan yang terdekat, dikenali oleh siswa dan ruang lingkupnya disesuaikan dengan usia dan perkembangan siswa, termasuk minat, 
kebutuhan, dan kemampuannya (Trianto, 2011). Dipertegas oleh kepala sekolah bahwa RPP kelas 2 sudah memenuhi kelengkapan komponen dalam pembuatan RPP. Salah satu model dalam pembelajaran terpadu yang merupakan suatu sistem pembelajaran yang memungkinkan siswa secara individual maupun kelompok, aktif menggali dan menemukan konsep serta prinsip-prinsip keilmuan secara menyeluruh, bermakna dan autentik adalah pembelajaran tematik (Rusman, 2012).

Dalam pelaksanaan pembelajaran tematik, guru harus membuat kegiatan yang didalamnya memberikan kesempatan pada siswa untuk berperan aktif dalam seluruh kegiatan. Seluruh kegiatan pembelajaran memberikan kesempatan siswa untuk menjawab dan bertanya. Dalam melaksanakan pembelajaran tematik di sekolah dasar, guru perlu menguasai berbagai macam kegiatan yang menarik. Siswa diberi kesempatan untuk menanyakan hal-hal yang berhubungan dengan materi yang kurang ia pahami.

Melalui pertanyaan-pertanyaan yang diajukan guru, siswa diarahkan untuk menemukan konsep yang sedang dipelajarinya. Dalam menemukan konsep, siswa juga dibimbing oleh guru agar tidak salah memahami konsep yang dipelajarinya. Saat guru menyampaikan materi pokok, guru menghubungkan materi tersebut dengan kehidupan seharihari siswa melalui pertanyaan-pertanyaan yang diajukan guru. Sesuai dengan teori Piaget, anak-anak mengonstruksi pengetahuan mereka berdasarkan pengalaman. Anak-anak tidak hanya mengumpulkan hal-hal yang telah mereka pelajari, mereka menggabungkan pengalaman-pengalamannya untuk memahami segala sesuatu yang berada di dunia (Antrock, 2011).

Depdiknas mendefinisikan penilaian dalam pembelajaran tematik adalah suatu usaha untuk mendapatkan berbagai informasi secara berkala, berkesinambungan, dan menyeluruh tentang proses dan produk dari pertumbuhan dan perkembangan yang telah dicapai peserta didik melalui kegiatan belajar (Depdiknas, 2006). Objek dalam penilaian pembelajaran tematik mencakup penilaian terhadap proses dan hasil belajar siswa. Penilaian proses belajar adalah upaya pemberian nilai terhadap kegiatan pembelajaran yang dilakukan oleh guru dan peserta didik. Berdasarkan hasil pengamatan yang peneliti lakukan di kelas 2 sebanyak dua kali, beberapa guru melakukan evaluasi proses, yaitu penilaian sikap. Untuk penilaian materi/konsep, semua guru menerapkannya di kelas sebagai tanggung jawab kepada sekolah dan dinas terkait.

Hambatan yang peneliti temui mengenai pembelajaran tematik di SD Negeri Demangan adalah kurangnya sosialisasi tentang pembelajaran tematik dari dinas terkait. Melalui sidak dan pengawasan secara berkala dari dinas pendidikan para guru mulai memahami bagaimana pembelajaran tematik. Untuk itu di setiap kelas dipasang CCTV.

Dalam pembuatan perencanaan pembelajaran, guru kelas rendah menemui beberapa hal yang menjadi perhatian utama dalam pembuatan RPP, yaitu dalam menentukan indikator-indikator yang saling berkaitan antara mata pelajaran satu dengan yang lain. Di tambah lagi dengan ruang kelas 2 yang sedang direnovasi sehingga pembelajaran hanya berlangsung dari jam 07.00 sampai 9.20 WIB saja karena setelah itu ada agenda kegiatan eksrtakurikuler.

Pada pelaksanaan pembelajaran tematik di kelas, ditemui juga beberapa persoalan yang terkait dengan kesulitan dalam mengaitkan materi antar mata pelajaran. Namun itu bisa diatasi dengan penggunaan media pembelajaran sehingga siswa aktif dan fokus dalam setiap pembelajaran tematik. Di akhir kegiatan pembelajaran, guru melakukan kegiatan evaluasi. Evaluasi yang selalu dilaksanakan 
oleh guru adalah evaluasi hasil belajar dalam bentuk tes tertulis.

\section{SIMPULAN DAN SARAN}

Berdasarkan hasil penelitian dan pembahasan, maka penelitian ini dapat disimpulkan, pertama pada tahap perencanaan, pembelajaran, dan penilaian sudah menggunakan pembelajaran tematik. Kedua hambatan-hambatan yang ditemui guru kelas rendah teratasi dengan baik dalam merencanakan, melaksanakan dan menilai pembelajaran tematik.

Saran yang diberikan adalah guru, bersama dengan sekolah dan dinas terkait hendaknya mengembangkan dan menambah pengetahuan tentang implementasi pembelajaran tematik terpadu, cara penerapan kegiatan saintitik, serta cara pelaksanaan penilaian otentik melalui KKG, atau seminar kurikulum 2013. Kepala sekolah hendaknya memotivasi guru agar dapat mengembangkan dan melaksanakan pembelajaran tematik terpadu dengan lebih baik, terutama berkaitan dengan kegiatan penliaian. Penelitian yang mengangkat pembahasan tentang implementasi pembelajaran tematik harus bersifat kontinuitas. Supaya hasilnya bisa menjadi pertimbangan untuk penelitian yang akan datang.

\section{DAFTAR PUSTAKA}

Antrock, J. W. (2011). Educational Psychology, Diana Angelica. Psikologi Pendidikan. Jakarta: Salemba Humanika.

Erlinda, N. (2017). Peningkatan Aktivitas dan Hasil Belajar Siswa melalui Model Kooperatif Tipe Team Game Tournament pada Mata Pelajaran Fisika di SMK. Tadris: Jurnal Keguruan Dan Ilmu Tarbiyah, 2(1), 47-52.

Gumrowi, A. (2016). Strategi Pembelajaran Melalui Pendekatan Kontekstual Dengan Cooperative Learning Untuk Meningkatkan Hasil
Belajar Gelombang Siswa Kelas XII MAN 1 Bandar Lampung. Jurnal Ilmiah Pendidikan Fisika Al-Biruni, 5(2), 183-191. https://doi.org/10.24042/jpifalbiruni. v5i2.118

Humaniora, J. P. (2011). Staf Pengajar FIP UNY. Jurnal Penelitian Humaniora, 16(1), 76-93.

Irwandani, I., \& Juariyah, S. (2016). Pengembangan Media Pembelajaran Berupa Komik Fisika Berbantuan Sosial Media Instagram sebagai Alternatif Pembelajaran. Jurnal Ilmiah Pendidikan Fisika Al-Biruni, 5(1), 33. https://doi.org/10.24042/jpifalbiruni. v5i1.103

Irwandani, I., \& Rofiah, S. (2015). Pengaruh Model Pembelajaran Generatif Terhadap Pemahaman Konsep Fisika Pokok Bahasan Bunyi Peserta Didik MTs Al-Hikmah Bandar Lampung. Jurnal Ilmiah Pendidikan Fisika Al-Biruni, 4(2), 165-177.

https://doi.org/10.24042/jpifalbiruni. v4i2.90

Juleha, S., Khuzaemah, E., \& Cahyani, D. (2014). Penerapan Strategi Belajar Murder Untuk meningkatkan Penguasaan Konsep Siswa Pada Pembelajaran Biologi Kelas VII MTs Al-Ikhlas Setupatok Cirebon. Jurnal Pendidikan Biologi FITK IAIN Syekh Nurjati Cirebon, 3(2), 95-109.

Kadir, A., \& Asrohah, H. (2015). Pembelajaran Tematik. Jakarta: PT Raja Grafindo Persada.

Kemendikbud. (2012). Dokumen

Kurikulum 2013. Jakarta:

Kemendikbud.

Komikesari, H. (2016). Peningkatan Keterampilan Proses Sains dan Hasil Belajar Fisika Siswa pada Model Pembelajaran Kooperatif Tipe Student Team Achievement Division. Tadris: Jurnal Keguruan Dan Ilmu Tarbiyah, 1(1), 15-22. 
Mulyadi, E. (2015). Penerapan Model Project Based Learning untuk Meningkatkan Kinerja dan Prestasi Belajar Fisika Siswa SMK. Jurnal Pendidikan Teknologi Dan Kejuruan, 22(4), 385-395.

Mulyadin. (2016). Implementasi Kebijakan Pembelajaran Tematik Terpadu Kurikulum 2013 Di SDN Kauman 1 Malang dan SD Muhammadiyah 1 Malang. Jurnal Edutama, 3(2), 31-48.

Prasetyo, T. (2017). Pengembangan Perangkat Penilaian Hasil Belajar dalam Pembelajaran TematikIntegratif Kelas V SD. Jurnal Prima Edukasia, 5(1), 102-111.

Rusman. (2012).

Model-Model Pembelajaran Mengembangkan Profesionalisme Guru. Jakarta: PT. Raja Grafindo Persada.

Saputro, H. B., \& Soeharto. (2015). Pengembangan Media Komik Berbasis Pendidikan Karakter Pada Pembelajaran Tematik-Integratif Kelas IV SD. Jurnal Prima Edukasia, 3(1), 61-72.

Sari, F. K., Farida, F., \& Syazali, M. (2016). Pengembangan Media Pembelajaran (Modul) berbantuan Geogebra Pokok Bahasan Turunan. Al-Jabar: Jurnal Pendidikan Matematika, 7(2), 135-151.

Wijayanti, W., Maharta, N., \& Suana, W. (2017). Pengembangan Perangkat Blended Learning Berbasis Learning Management System pada Materi Listrik Dinamis. Jurnal Ilmiah Pendidikan Fisika Al-Biruni, 6(1), 112.

Yanti, A. P., \& Syazali, M. (2016). Analisis Proses Berpikir Siswa dalam Memecahkan Masalah Matematika Berdasarkan LangkahLangkah Bransford dan Stein Ditinjau dari Adversity Quotient. AlJabar: Jurnal Pendidikan Matematika, 7(1), 63-74.

Yulianti, D., \& Putra, N. M. D. (2012).
Upaya Mengembangkan Learning Community Siswa Kelas X SMA Melalui Penerapan Model Pembelajaran Kooperatif Tipe STAD Berbasis CTL Pada Pembelajaran Fisika. Jurnal Pendidikan IPA Indonesia, 1(1), 57-62. 